\title{
Forming architectured paper by printing a starch patterned grid: a new low-cost approach for lightweighting packaging
}

\author{
Jérémie Viguié (iD) - Richard Thalhofer - William Gourgeon - Laura Crowther-Alwyn • \\ Kevin Lamontagne $\cdot$ Robin Abderrahmen $\cdot$ Caroline Locre $\cdot$ David Guérin
}

Received: 3 March 2021 / Accepted: 9 May 2021 / Published online: 19 May 2021

(C) The Author(s) 2021

\begin{abstract}
To meet the environmental challenges, the use of plastic packaging must be drastically reduced. Paper-based solutions may be a credible alternative provided that their production cost is reduced. One way may be to improve the paper stiffness to weight ratio. In this work, a simple and low-cost approach is proposed, which consists in printing a patterned grid of starch at the paper surface by using a widespread printing process. With only a small quantity of starch $\left(7 \mathrm{~g} / \mathrm{m}^{2}\right)$, the bending stiffness of a packaging paper of $60 \mathrm{~g} / \mathrm{m}^{2}$ was multiplied by more than a factor three. This improvement originates from the permanent 3D shape the paper unexpectedly took after printing. The printed lines formed "valleys" whereas the unprinted zones were raised, forming "mountains". Drying shrinkage of the starch is assumed to play a major
\end{abstract}

J. Viguié $(\bowtie)$ · W. Gourgeon · L. Crowther-Alwyn ·

K. Lamontagne - C. Locre · D. Guérin

Centre Technique du Papier (CTP), 38044 Grenoble,

France

e-mail: jeremie.viguie@1gp2.grenoble-inp.fr

J. Viguié

Laboratory of Pulp and Paper Science and Graphic Arts

(LGP2), Université Grenoble Alpes, Grenoble, France

R. Thalhofer

Cargill Deutschland, 47809 Krefeld, Germany

R. Abderrahmen

Ahlstrom-Munksjö Specialties, 38780 Pont-Evêque,

France role, in particular by inducing local buckling of the unprinted zones. In addition, the resulting 3D shape could be interestingly tuned by adjusting the grid pattern. Even if a better understanding is necessary to be able to well control the phenomena, this approach appears relevant to form "architectured" papers with improved bending resistance to weight ratio.

Keywords Paper $\cdot$ Starch $\cdot$ Screen printing $\cdot$ Bending stiffness $\cdot$ Architectured material

\section{Introduction}

Paper is a mostly bio-sourced, recyclable and fully biodegradable material. Regarding environmental issues, paper offers an interesting alternative to plastic. More and more actors of the packaging value chain make efforts to reduce their use of plastic packaging. In this context, the demand for paper-based packaging has never been greater. Innovative surface treatments have been developed to give paper the required barrier properties or sealing ability while guaranteeing it remains biodegradable and recyclable (Johansson et al. 2012). However, the production cost of these new papers must be reduced to make the switch from plastic to paper economically viable. One efficient way may be to decrease the paper weight while maintaining suitable levels of stiffness and strength (Hubbe 2014). 
Paper has an interesting strength to weight ratio. A packaging paper of $60 \mathrm{~g} / \mathrm{m}^{2}$ has an elastic modulus of 5-7 GPa for a tensile strength close to $100 \mathrm{MPa}$. Mechanical properties of paper are piloted by fibre's mechanical behaviour and low energy chemical bonding at fibre-fibre contacts developed when water is expelled during paper forming. Fibres bond to each other by several mechanisms: mechanical interlocking, Coulomb forces, hydrogen bonding and Van der Waals forces (Hubbe, 2006, Hirn \& Schennach 2015). Besides, cationic polymers are often used to enhance the paper strength (Lindstrom et al. 2005). They (i) increase the specific bond strength by developing the area in molecular contact, enhancing molecular interactions, (ii) improve the sheet density and the potential bonding area, as well as (iii) decrease stress concentrations in the fibre network initiated during drying. Among them, cationic starch is one of the most used. Micro-fibrillated cellulose (MFC), introduced at the wet end, can also significantly strengthen paper by activating the physical mechanisms (i) and (ii) (Lindstrom et al. 2016)

However, as strength improving strategies often result in reducing the paper thickness, they may lead to reduce its bending stiffness, knowing that bending stiffness varies according to the moment of inertia of the paper cross-section (Fellers \& Carlsson 2002). Packaging material often requires bending stiffness to ensure box panels buckling resistance (Viguié \& Dumont 2013) or self-standing ability in the case of flexible packaging (e.g. dry food stand up pouches). Designing embossed or ribbed plate or shell structures is relevant to improve the moment of inertia of the cross section and accordingly the bending stiffness to weight ratio of materials (Huybrechts et al. 1999; Laszczyk 2011). Indeed, these structures are widely present in nature and used extensively in transports and constructions (Wang et al. 2019). Bending and buckling performances are mainly controlled by the geometry of the ribs and the network they form (Akl et al. 2008; Wang et al. 2019) or by the embossing pattern or depth (Laszczyk 2011). The mechanical performance may be specifically improved by using auxetic patterned structures (Smardzewski 2013). Recently, they have been interestingly printed on the surface of fabrics (Kabir et al. 2020). This kind of designs endows the core structure with the ability to adapt to a bending force by forming a dome with double curvature (Ren et al. 2018).
As mentioned earlier, starch is widely used in papermaking for enhancing paper strength by adding in the wet or dry end, as well as for surface finishing by coating on the paper surface (Li et al. 2019). Starch is a very low cost, bio-sourced, fully biodegradable and highly available product. Besides, it can form selfstanding films after a gelatinization step with interesting mechanical properties provided that it is slightly plasticized (Viguié et al. 2007). In this work, we studied the potential of printing a starch-based patterned grid on a packaging paper to improve its bending resistance. Screen printing was used since it is the most common industrial process that can provide suitable thickness of printed lines. Starch was interestingly and unusually used as an ink. In the following, the first section is dedicated to the description of the grid printing approach. Then, the structural features of the printed papers are described and their mechanical performances are displayed. Finally, results are discussed in order to give some insights on the underlying phenomena responsible for the resulting features and performances of the printed papers.

\section{Material \& methods}

\section{Materials}

An industrial paper of $60 \mathrm{~g} / \mathrm{m}^{2}$ from AlhstromMunksjo was mainly used in this study. It is made of slightly refined chemical pulp from hardwood $(70 \%)$ and softwood (30\%), calendered and coated with $10 \mathrm{~g} /$ $\mathrm{m}^{2}$ of a formulation of mineral pigments (precipitated calcium carbonate and kaolin) and latex. Its final thickness is $58 \mu \mathrm{m}$. Two other papers of $70 \mathrm{~g} / \mathrm{m}^{2}$ were also used for comparison: a high-density paper (tracing paper) of $63 \mu \mathrm{m}$ thickness, made of $100 \%$ highly refined chemical pulp without coating step, and a low-density paper (blotting paper) of $125 \mu \mathrm{m}$ thickness, made of $100 \%$ unrefined chemical pulp.

\section{Printing approach}

\section{Ink formulation}

The starch-based formulation was prepared from a thermo-modified corn starch with low molecular weight from the Cargill Company. It was cooked at $90{ }^{\circ} \mathrm{C}$ for $30 \mathrm{~min}$ with a suitable quantity of water to 
obtain a solution with a viscosity of $1350 \mathrm{mPa}$.s at $60^{\circ}$. Its final dry content was around $40 \mathrm{wt} \%$.

\section{Screen printing}

The screen-printing machine used in this work is a semi-automatic printer (EKRA Serio E2), easy-tohandle and suitable for laboratory printings. The formulation was put on the screen at the working temperature with a syringe (Fig. 1a). Then, the mobile table with the sample to print went under the screen, the squeegee made the ink going through the screen with set speed, pressure and angle (Fig. 1b). Due to the small volume of ink on the screen, the temperature went down very quickly to the temperature of the lab. Finally, the printing sample was dried at $60^{\circ} \mathrm{C}$ for $2 \mathrm{~min}$ in an oven.

\section{Grid patterns}

Several grid patterns were investigated in this study. For beginning, we focused on orthogonal patterns with lines, spaced of $5 \mathrm{~mm}$, of different widths: $0.75 \mathrm{~mm}$ (Fig. 2a), $1 \mathrm{~mm}, 1.5 \mathrm{~mm}$ (Fig. 2b), $2 \mathrm{~mm}$ and $2.5 \mathrm{~mm}$ (Fig. 2c). Each configuration results in different covering ratios $(\mathrm{CoR})$, i.e. \% of printed surface: $19 \%, 27 \%, 51 \%, 64 \%$ and $75 \%$. Thereafter, three other grid patterns were studied: a honeycomb-type (Fig. 2d), a re-entrant-type (Fig. 2e) and a sinusoidal-type (Fig. 2f), with a line width of $1 \mathrm{~mm}$ and specific dimensions to have a CoR of $27 \%$. The last two are known to form structures with an auxetic behaviour (Ren et al. 2018).
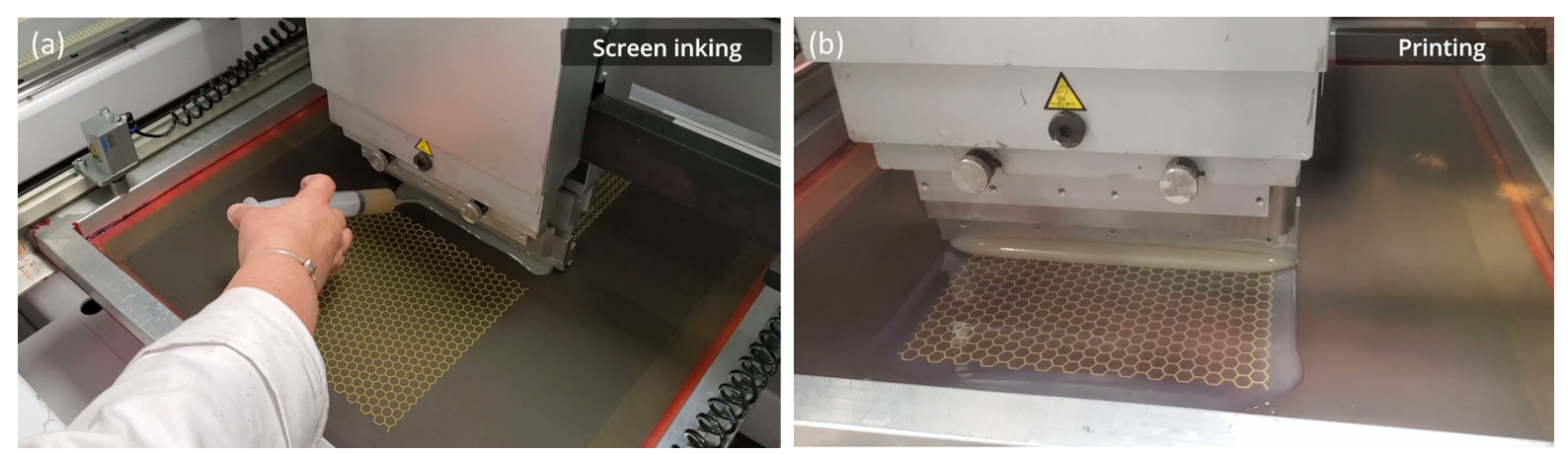

\section{Characterization}

The printed paper thickness was measured following the standard ISO 12,625-3 adapted to compressible structures, which consists in measuring the gap between two flat platens that compress the paper at $2 \mathrm{kPa}$. The printed paper surface topography was characterized by laser profilometry using a 3D-Map ${ }^{\circledR}$ (Techpap, Grenoble, France). The printed paper cross section was observed using a microtom RM 2125 RTS (Leica Biosystems, Nanterre, France) after the sample was embedded in acrylate and stained with iodine to enhance the contrast between starch and fibres. The bending behaviour was characterized by performing two points bending tests following ISO 2493-1 and the tensile strength was measured following ISO 1924-2. All the tests were carried out in a conditioned atmosphere at $23{ }^{\circ} \mathrm{C}$ and $50 \%$ RH. Before testing all the samples were pre-conditioned at $30{ }^{\circ} \mathrm{C}$ and $33 \%$ RH during $24 \mathrm{~h}$, and then conditioned $23{ }^{\circ} \mathrm{C}$ and $50 \%$ RH during an additional $24 \mathrm{~h}$.

\section{Results}

Structural features of the printed papers

Figure 3a shows a top view of the surface topography of a printed line from the orthogonal pattern grid printed paper of Fig. 2b. Its width was rather aligned with that of the screen pattern. The deviation was lower than $0.2 \mathrm{~mm}$ along the line length, suggesting that the starch formulation did not spread out too much after deposit. The thickness of the printed layer was around $15-17 \mu \mathrm{m}$ (Fig. 3b). It was rather homogeneous on the whole printed surface. The evolution of

Fig. 1 Starch grid screen printing main stages 
(a)

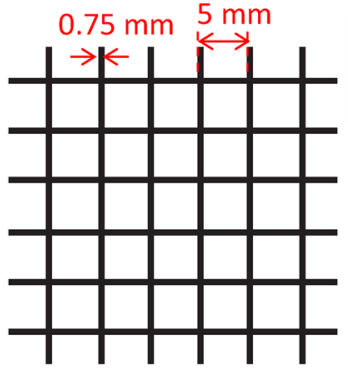

(d)

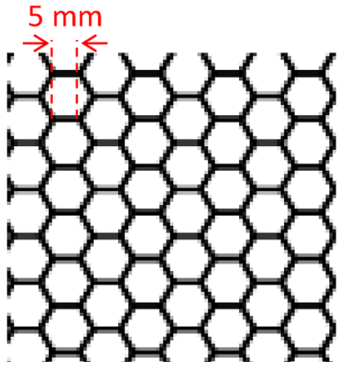

(b)

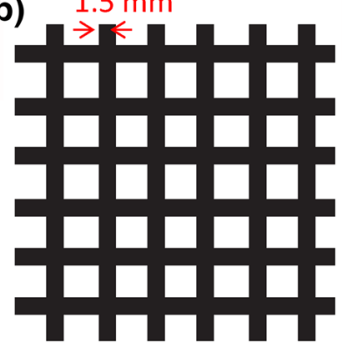

(e)

$10 \mathrm{~mm}$

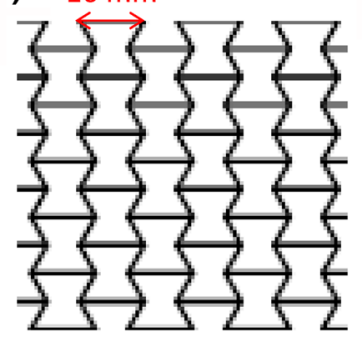

(c)

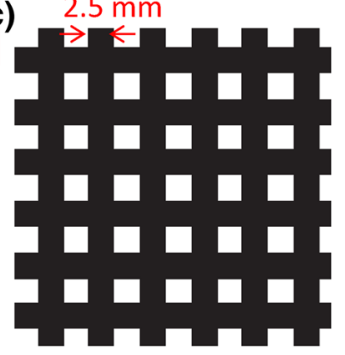

(f)

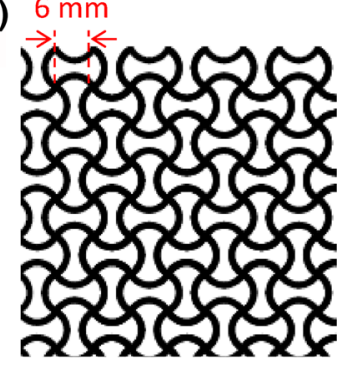

Fig. 2 Grid patterns deposited by screen printing on the paper surface. Orthogonal patterns with different line widths and covering ratios (CoR) a $19 \%$, b $51 \%$ and c $75 \%$. d Honeycomb
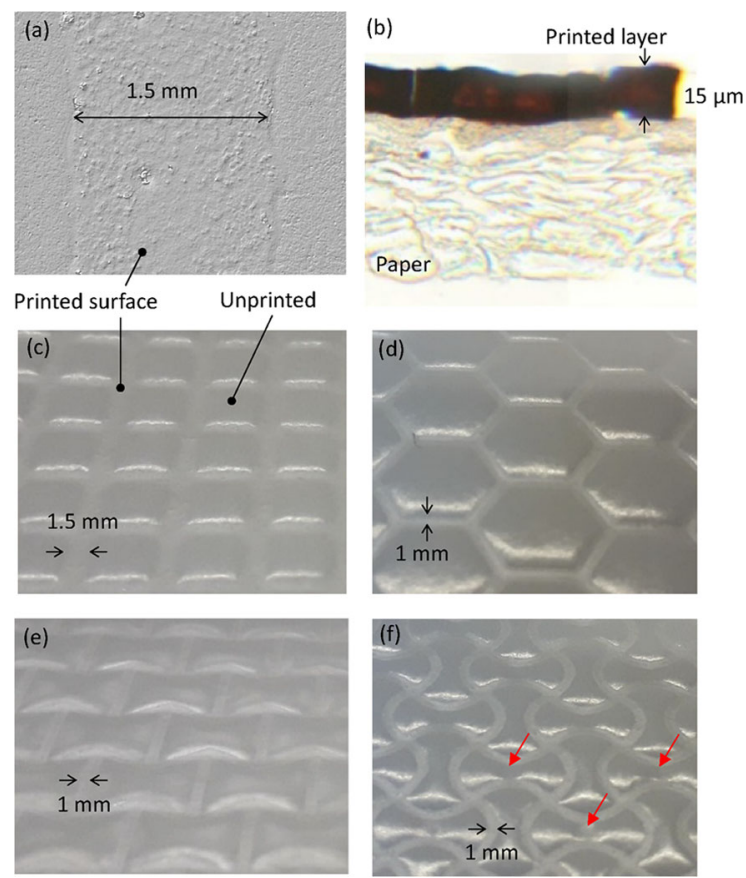

Fig. 3 a Top surface and $\mathbf{b}$ cross section of the printed paper with the re-entrant grid pattern. Cross-section was obtained using a microtom after the sample was embedded in acrylate and stained with iodine. Pictures of the printed side of the paper with $\mathbf{c}$ an orthogonal grid, $\mathbf{d}$ a honeycomb grid, $\mathbf{e}$ a re-entrant grid and f a sinusoidal grid pattern, e re-entrant pattern and $\mathbf{f}$ sinusoidal pattern with $1 \mathrm{~mm}$ line width and $27 \%$ of $\mathrm{CoR}$

the basis weight of the printed paper with the CoR (Table 1) was in accordance with the measured thickness considering the starch density is around $1.5 \mathrm{~g} / \mathrm{cm}^{3}$.

One can notice that the starch did not penetrate in the paper thickness. It was expected regarding the closed structure of the paper on this side, resulting from the calendering operation and surface coating. Furthermore, no crack was observed in the printed starch layer, as it may develop when starch dries without plasticizer. The gentle drying conducted in an oven at $60{ }^{\circ} \mathrm{C}$ surely contributed to limit this phenomenon. Besides, bonding between the starch and the paper surface was excellent, no delamination phenomenon was observed. It was expected as the starch formulation is typically used for paper coating.

Figures 3(c-f) depict pictures took with a grazing incidence of the printed side of the papers with the four different grid patterns after drying. The printed papers showed systematically an unexpected 3D permanent deformation. The printed lines formed "valleys" whereas the unprinted zones were raised, forming "mountains". The phenomenon occurred whatever the grid pattern. It can be seen as a kind of local buckling. Thus, orthogonal grid printing formed regularly arranged square base domes (Fig. 3c), 
Table 1 Structural features and mechanical performances of the printed papers with an othogonal grid at different covering ratios (CoRs)

\begin{tabular}{|c|c|c|c|c|c|c|c|}
\hline & & Paper & $19 \%$ & $27 \%$ & $51 \%$ & $64 \%$ & $75 \%$ \\
\hline Basis weight $\left(\mathrm{g} / \mathrm{m}^{2}\right)$ & & $60.0 \pm 0.3$ & $64.9 \pm 1.2$ & $67.2 \pm 0.7$ & $72.6 \pm 2.8$ & $75.2 \pm 0.8$ & $77.7 \pm 1.3$ \\
\hline Thickness $(\mu \mathrm{m})$ & & $58 \pm 2$ & $141 \pm 14$ & $190 \pm 19$ & $247 \pm 32$ & $256 \pm 17$ & $240 \pm 15$ \\
\hline \multirow[t]{2}{*}{ Tensile strength $(\mathrm{kN} / \mathrm{m})$} & MD & $3.6 \pm 0.1$ & $3.6 \pm 0.2$ & $3.6 \pm 0.2$ & $3.6 \pm 0.2$ & $3.5 \pm 0.1$ & $3.4 \pm 0.2$ \\
\hline & $\mathrm{CD}$ & $2.0 \pm 0.1$ & $2.0 \pm 0.1$ & $2.0 \pm 0.1$ & $1.9 \pm 0.1$ & $1.9 \pm 0.1$ & $1.9 \pm 0.1$ \\
\hline \multirow[t]{2}{*}{ Bending stiffness (mN.m) } & MD & $0.08 \pm 0.02$ & $0.35 \pm 0.08$ & $0.38 \pm 0.10$ & $0.55 \pm 0.13$ & $0.53 \pm 0.15$ & $0.53 \pm 0.18$ \\
\hline & $\mathrm{CD}$ & $0.05 \pm 0.02$ & $0.15 \pm 0.05$ & $0.18 \pm 0.07$ & $0.22 \pm 0.08$ & $0.30 \pm 0.10$ & $0.28 \pm 0.12$ \\
\hline \multirow[t]{2}{*}{ Calculated from Eq. (1) } & MD & & 0.49 & 1.16 & 2.18 & 2.17 & 1.83 \\
\hline & $\mathrm{CD}$ & & 0.31 & 0.72 & 1.36 & 1.35 & 1.14 \\
\hline
\end{tabular}

honeycomb grid printing formed hexagonal base domes (Fig. 3d) and re-entrant grid printing formed dome-like structures with a base that well fitted the reentrant grid pattern (Fig. 3e). The shape of the sinusoidal grid printed paper was more complex (Fig. 3f). Note that it was rather similar when the sinusoidal grid was printed on a high-density paper or a low-density paper.

Figure 4 displays the topography maps of the printed papers with the different orthogonal grids. The formed 3D structure was highly homogeneous: each square dome was quite similar in shape and elevation. While the CoR increased, the base of the squares decreased whereas their maximum height increased. However, to accurately quantify the overall thickness of the deformed printed paper, the standardized method ISO 12,625-3 was preferred. Values are recorded in Table 1 . The overall thickness was improved by $150 \%$ when the CoR was $19 \%$, more than $200 \%$ when the CoR was $27 \%$ and $300 \%$ when the CoR was $51 \%$. Beyond, the overall thickness no longer increased (Fig. 4d and e).

Figures 5a and $\mathrm{b}$ show the topography maps of the papers printed with the re-entrant grid pattern and the sinusoidal grid pattern, respectively. The re-entrant one formed domes which were well homogeneous in shape and maximum height. It must be pointed out that this height was greater than that of the paper with the orthogonal grid at the same CoR (27\%) and quasi equivalent to that of the papers with the orthogonal grid at $51 \%$ and beyond CoR (Table 2). Note that it was quite the same for the paper printed with the honeycomb grid (Table 2).
As already mentioned, the deformed shape of the printed paper with the sinusoidal grid was more complex. When the unprinted zones were aligned along the machine direction of the paper (MD), they formed elongated domes; whereas they did not take uniform mountain shape when they were aligned along the cross direction of the paper (CD). They displayed several buckling waves. As a result, they buckled downward in the middle. The phenomenon is pointed out by red arrows in Fig. $3 f$ and Fig. $5 b$. Furthermore, the overall thickness of this paper was slightly lower than that of the papers with the reentrant and honeycomb grids (Table 2). Figures 6a and $b$ present the topography maps we get when the sinusoidal grid was printed on the low-density paper and on the high-density paper, respectively. The deformed shape of the printed high-density paper was regular and homogeneous and the downward buckling phenomenon was marked (see red arrows). The gain in overall thickness was huge $(+350 \%)$ (Table 3). The deformed shape of the printed blotting paper was well apparent but less pronounced. Located downward buckling was also seen. Thus, the gain in overall thickness was lower $(+50 \%)$ (Table 3$)$.

Mechanical performance of the printed papers

The in-plane and out-of-plane mechanical properties of the printed papers were assessed by performing tensile and two-point bending tests. No evolution of the tensile strength was observed neither in the machine direction (MD) nor in the cross direction (CD) whatever the CoR (Table 1), the grid pattern (Table 2 ) or the paper density (Table 3 ). No evolution 


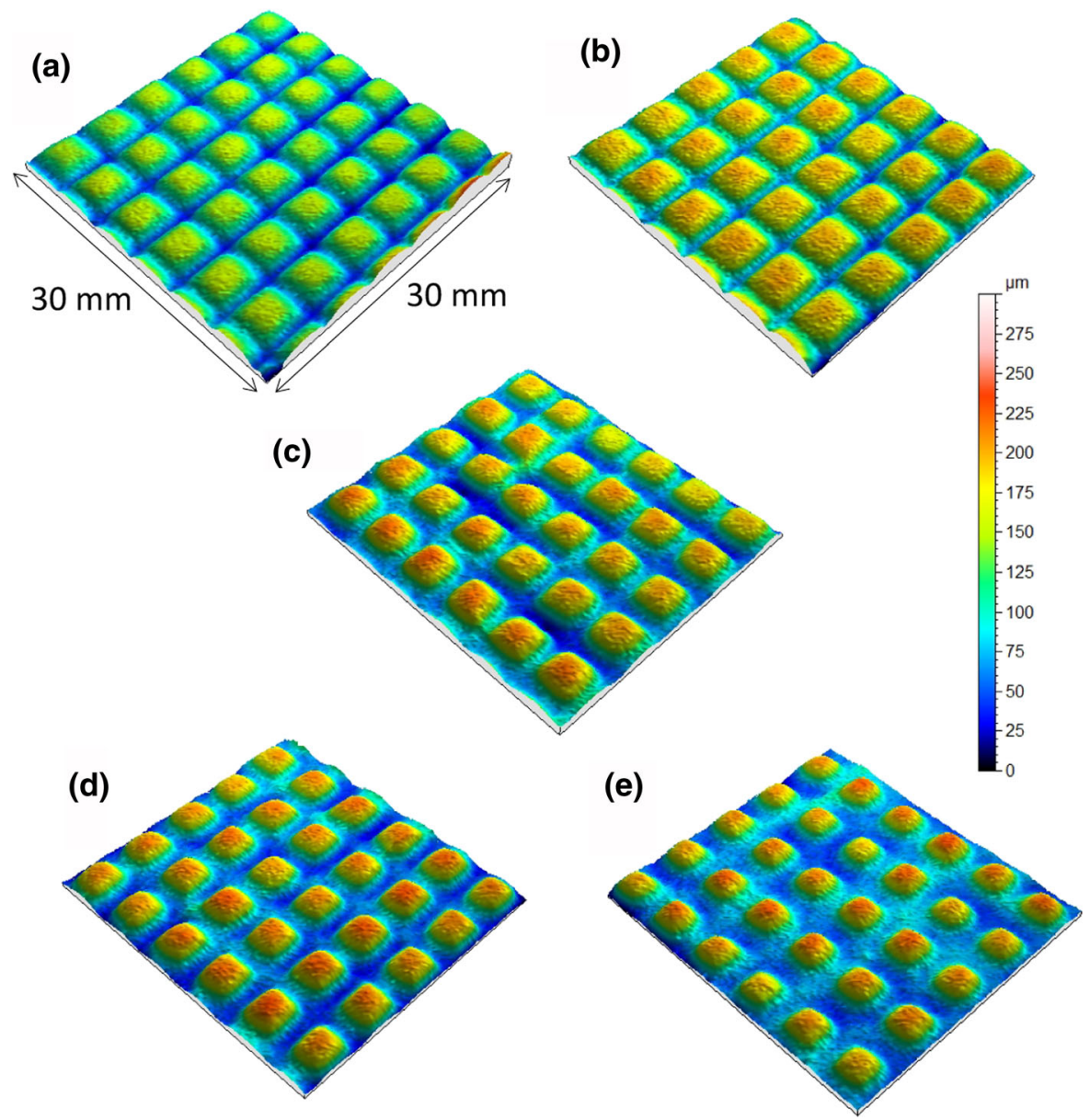

Fig. 4 Topography maps of the orthogonal grid printed paper with a covering ratio (CoR) of a 19\%, b $27 \%$, c 51\%, d $64 \%$ and e $75 \%$

(a)

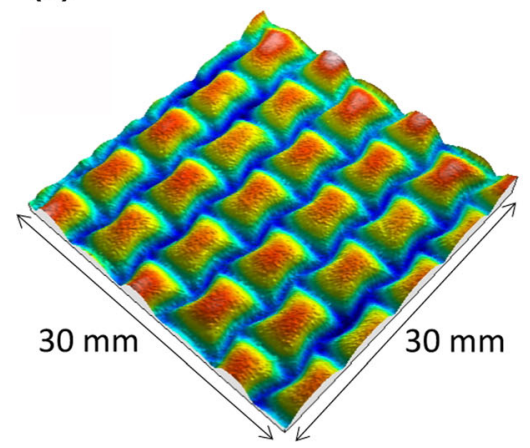

(b)

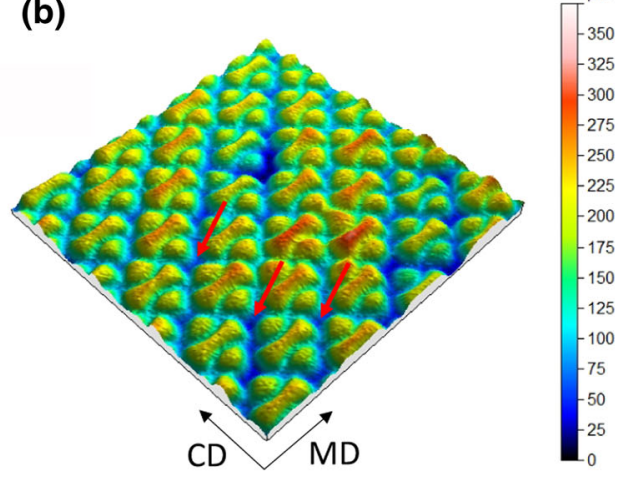

Fig. 5 Topography maps of $\mathbf{a}$ the re-entrant grid printed paper and $\mathbf{b}$ the sinusoidal grid printed paper

of the breaking strain was noticed either. As a conclusion, the permanent paper deformation induced by printing would not so much alter the intrinsic properties of the fibre network, even if the presence of starch at the paper surface could counteract a potential loss of properties.

In contrast, the bending performance was drastically improved with grid printing. The bending 
Table 2 Structural features and mechanical performances of the printed papers with different grid patterns (at 27\% CoR)

\begin{tabular}{llllll}
\hline & & Orthogonal & Honeycomb & Re-entrant & Sinusoidal \\
\hline Basis weight $\left(\mathrm{g} / \mathrm{m}^{2}\right)$ & & $67.2 \pm 0.7$ & $64.6 \pm 0.7$ & $65.5 \pm 0.7$ & $67.6 \pm 1.0$ \\
Thickness $(\mu \mathrm{m})$ & & $190 \pm 19$ & $251 \pm 13$ & $249 \pm 28$ & $218 \pm 10$ \\
Tensile strength $(\mathrm{kN} / \mathrm{m})$ & $\mathrm{MD}$ & $3.6 \pm 0.2$ & $3.3 \pm 0.4$ & $3.6 \pm 0.1$ & $3.3 \pm 0.3$ \\
& $\mathrm{CD}$ & $2.0 \pm 0.1$ & $1.9 \pm 0.1$ & $1.9 \pm 0.1$ & $1.9 \pm 0.0$ \\
Bending stiffness (mN.m) & MD & $0.38 \pm 0.10$ & $0.33 \pm 0.08$ & $0.45 \pm 0.13$ & $0.45 \pm 0.13$ \\
& $\mathrm{CD}$ & $0.18 \pm 0.08$ & $0.28 \pm 0.08$ & $0.20 \pm 0.03$ & $0.28 \pm 0.15$ \\
\hline
\end{tabular}
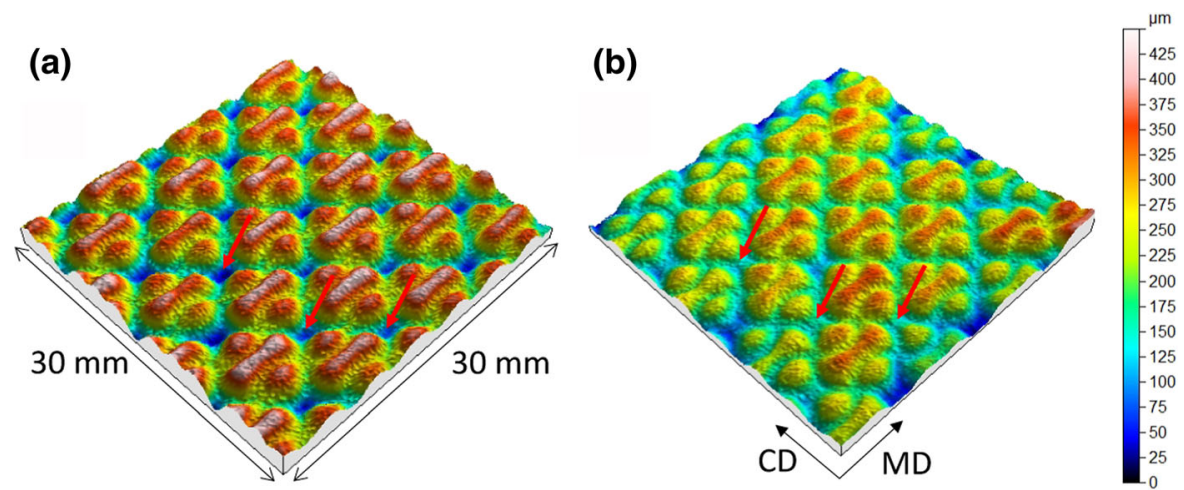

Fig. 6 Topography maps of a the high-density paper (tracing paper) and $\mathbf{b}$ the low-density paper (blotting paper), after printing of the sinusoidal pattern grid

Table 3 Structural features and mechanical performances of the highdensity and low-density papers, before and after grid printing (sinusoidal pattern, $27 \%$ CoR)

\begin{tabular}{llllll}
\hline & \multicolumn{3}{c}{ Tracing paper } & \multicolumn{3}{l}{ Blotting paper } \\
\hline Basis weight $\left(\mathrm{g} / \mathrm{m}^{2}\right)$ & & $70.4 \pm 0.3$ & $85.7 \pm 0.7$ & $69.6 \pm 0.3$ & $82.9 \pm 0.3$ \\
Thickness $(\mu \mathrm{m})$ & & $64 \pm 1$ & $289 \pm 9$ & $125 \pm 2$ & $193 \pm 3$ \\
Tensile strength $(\mathrm{kN} / \mathrm{m})$ & $\mathrm{MD}$ & $6.9 \pm 0.3$ & $6.2 \pm 0.2$ & $4.1 \pm 0.2$ & $4.3 \pm 0.2$ \\
& $\mathrm{CD}$ & $3.1 \pm 0.1$ & $3.2 \pm 0.3$ & $2.4 \pm 0.1$ & $2.4 \pm 0.1$ \\
Bending stiffness $(\mathrm{mN} . \mathrm{m})$ & $\mathrm{MD}$ & $0.30 \pm 0.03$ & $0.50 \pm 0.05$ & $0.18 \pm 0.03$ & $0.68 \pm 0.15$ \\
& $\mathrm{CD}$ & $0.15 \pm 0.03$ & $0.43 \pm 0.05$ & $0.08 \pm 0.03$ & $0.35 \pm 0.10$ \\
\hline
\end{tabular}

moment was plotted as a function of the bending curvature in Fig. $7 \mathrm{a}$ and $\mathrm{b}$ for the papers printed with the different orthogonal patterns, in $\mathrm{MD}$ and $\mathrm{CD}$ respectively. For all the considered CoRs, the bending moment increased linearly with the curvature until $7-10 \mathrm{~m}^{-1}$. This first slope corresponds to the bending stiffness. Values are recorded in Table 1 . The bending stiffness was multiplied by a factor close to four when the paper was printed with a $27 \% \mathrm{CoR}$ grid, and by a factor six with a $51 \%$ CoR grid. In CD, differences were only slightly lower. Beyond $7-10 \mathrm{~m}^{-1}$ of curvature, the bending moment increased with a slightly lower slope until the highest investigated curvature $\left(35 \mathrm{~m}^{-1}\right)$. The slope reduction was more important for the lowest CoRs. It is worth noting that increasing the CoR beyond $51 \%$ did not have any significant impact on the paper bending behaviour.

When comparing the grid pattern, the paper with the sinusoidal one showed the highest bending stiffness in both directions (Table 2). Compared with the base paper, the bending stiffness was improved by more than $450 \%$ in both directions. The re-entrant pattern grid had the same stiffness in MD but a lower one in $\mathrm{CD}$. This discrepancy could originate from the anisotropy of this pattern. Note that, on the contrary, the honeycomb pattern seemed to give the printed paper a more isotropic behaviour. The best performances obtained in MD with the "auxetic" patterns 


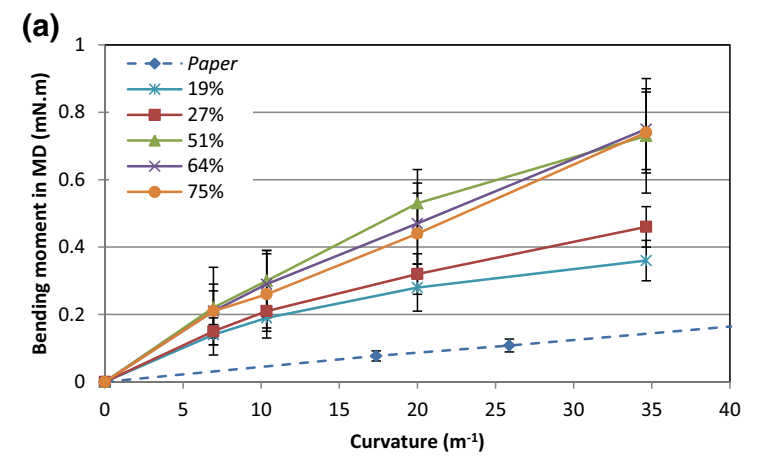

(b)

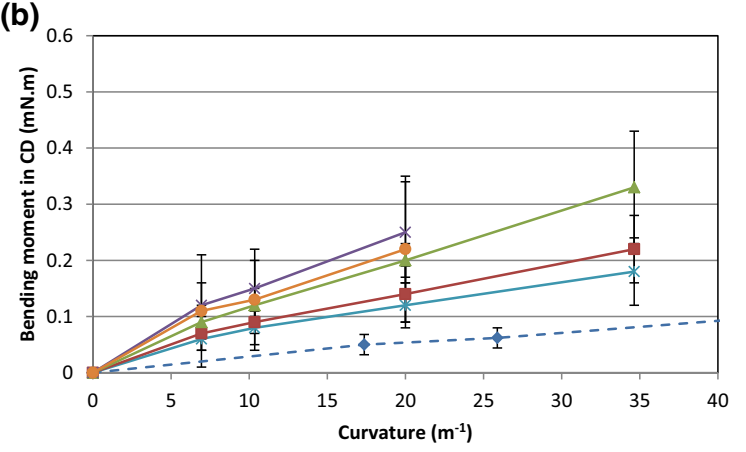

Fig. 7 Evolution of the bending moment with the bending curvature of the printed papers with an orthogonal grid at different CoRs, $\mathbf{a}$ in the machine direction (MD) and $\mathbf{b}$ in the cross direction (CD), when performing two-points bending test according to the ISO 2493-1 standard

could result from the specific geometrical and mechanical properties these patterns confer (Ren et al. 2018). However deeper experimental characterizations are needed to conclude.

Moreover, regarding the other paper types, the improvement was slightly lower but still pronounced: it reached $60 \%$ in MD for the high-density paper and $270 \%$ for the low-density paper (Table 3 ).

\section{Discussion}

Understanding of bending performance and resulting lightweigting

The improvement in bending performance that we get by only printing a starch grid for an equivalent weight of $7 \mathrm{~g} / \mathrm{m}^{2}(27 \% \mathrm{CoV})$ or $10 \mathrm{~g} / \mathrm{m}^{2}(51 \% \mathrm{CoV})$ was huge ( $\times 4$ and $\times 6$ respectively) and unexpected. It could result from the $3 \mathrm{D}$ shape the printed paper permanently took after drying. The moment of inertia of the paper cross section could be greatly improved.
One could accurately predict the bending stiffness of this kind of "architectured" material using numerical approaches [10]. It is not the purpose of this paper, nevertheless a rough approximation can be given by using an available analytical solution for corrugated sheets of Eq. (1) from Cao and Huang (2018), wherein the bending stiffness $D$ is expressed as a function of the paper in-plane Young modulus $E$ and of the geometrical parameters of the cross-section. These parameters were roughly deduced from the measured topographic profile (Fig. 4) and by considering the initial paper thickness $t$ (Fig. 8).

$D=\frac{E}{2 a}\left(b t h^{2}+\frac{t}{3 \sin \theta} h^{3}\right)$

The calculated bending stiffnesses are presented in Table 1. They differed from the experimental one: they were significantly greater. These discrepancies were higher as the CoR increased. They could be due to the strong approximation made on the cross-section shape or to the damage phenomena that could occur at the fibre network scale when the paper was being deformed. Note that the damage would be obviously greater with the deformation magnitude. Further investigations are needed to conclude. Nevertheless, the magnitude of the theoretical stiffness gain gives an idea of the potential of this approach to improve the paper bending stiffness to weight ratio.

In order to (roughly) estimate the lightweighting that could be achieved, we calculated the thickness $(t)$ of the theoretical paper with the same composition, density and Young modulus than the base paper and with the same bending stiffness than the paper printed with the sinusoidal grid (27\% CoR) (Table 2$)$ by using the simple relationship from the beam theory of Eq. (2).

$t=\left(\frac{12 D}{E}\right)^{1 / 3}$

The calculated thickness $t$ reached a value around $100 \mu \mathrm{m}$. As a result, the basis weight would be around $100 \mathrm{~g} / \mathrm{m}^{2}$. As a conclusion, if we consider only the bending stiffness, a paper of $100 \mathrm{~g} / \mathrm{m}^{2}$ could be theoretically replaced by a printed paper of $60 \mathrm{~g} / \mathrm{m}^{2}$ with $7 \mathrm{~g} / \mathrm{m}^{2}$ of starch: the weight could be reduced by $33 \%$. If we assume that the cost of the starch is $30 \%$ higher than the cost of the paper pulp $(1 € / \mathrm{kg} v s 0.7 € /$ $\mathrm{kg}$ ), the raw material cost could be reduced by $30 \%$. 


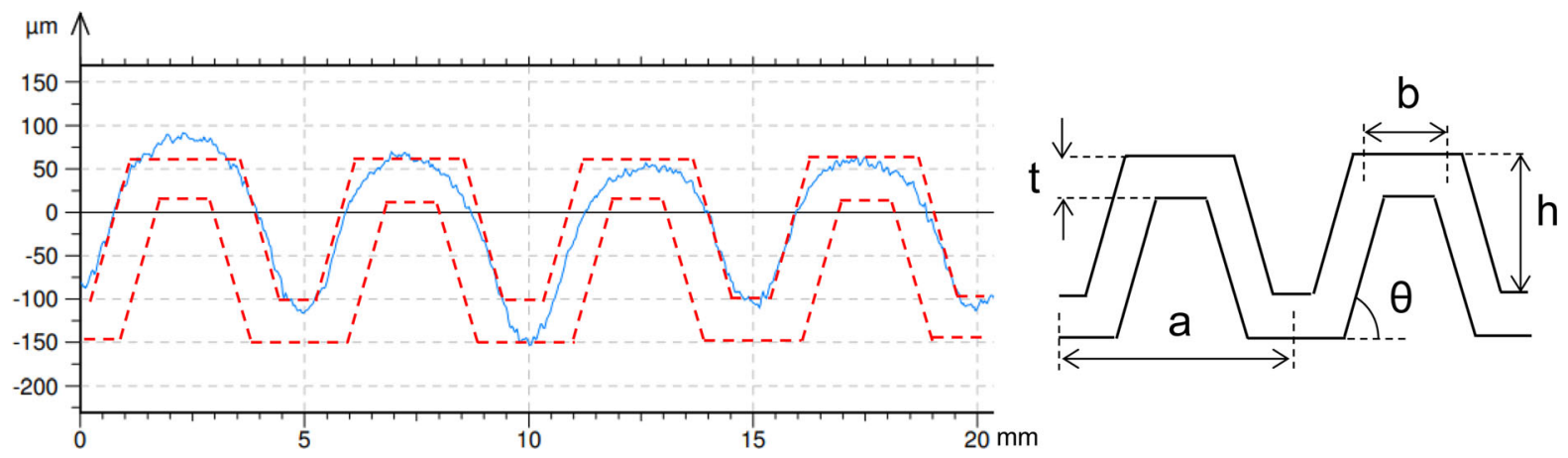

Fig. 8 Geometrical parameters of the approximated corrugated shape of the cross section of the printed paper with the orthogonal grid

Understanding of the underlying phenomena

However, to take full advantage of this approach, the paper deformation obtained by printing and drying must be controllable. This requires to understand the underlying phenomena. At the present time, we are able to only give some first insights on their understanding. As the starch "ink" is made of $60 \%$ of water, it shrinks when it dries. At the same time, some low energy chemical interactions are being developed between the starch macromolecules and the polymers on the paper surface (i.e. cellulose for tracing and blotting papers, and latex for the coated paper), eased by the water intake that soften them. This water may also help weaken fibre-fibre bonding. A part of the stresses initiated at drying during the papermaking process may be released. Thus, the fibre network may be free to re-arrange for a moment. It may be more likely to follow the starch shrinkage along the printed lines. The inherent shrinkage of the fiber network allowed by stress release could also contribute to the shrinkage. We do not know its actual contribution, but we can provide some first elements of answer. The shrinkage of the fibre network is known to differ between the MD and the CD (Niskanen, 1998). However, we did not observe any anisotropy in the raised structures (except on the local buckling shape in the paper with the sinusoidal pattern, which would be related to the anisotropic behaviour of the unprinted areas). This observation suggests that shrinkage along the printed lines would be mainly piloted by starch shrinking.

Then, the unprinted areas may be subjected to axial compression in both directions. This load may be high enough to exceed the critical buckling load of the paper, and it buckles between the printed lines.

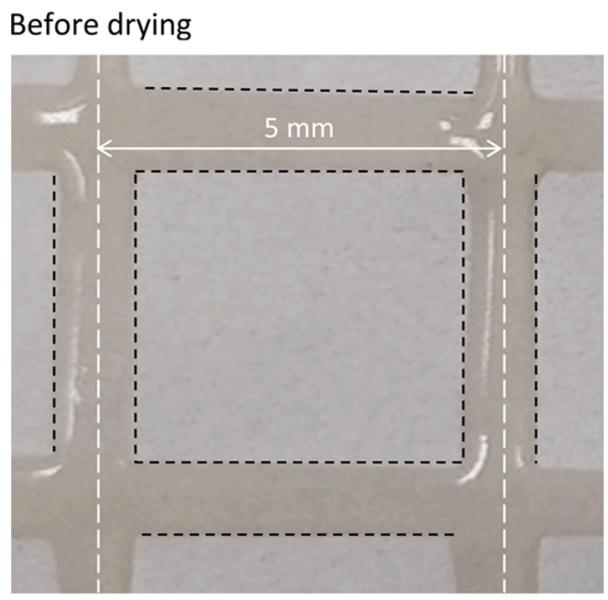

After drying

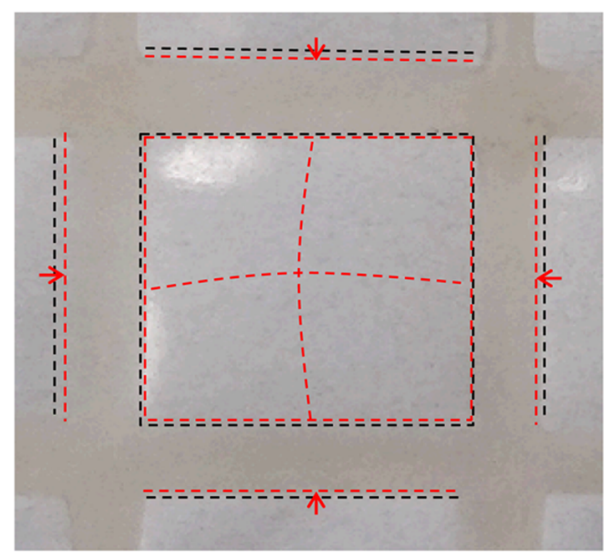

Fig. 9 Pictures of the orthogonal grid pattern printed on the Gerstar paper before and after drying in an oven at $60{ }^{\circ} \mathrm{C}$. Here, starch was deposited using a syringe attached to a XY table

Figure 9 displays a piece of paper where the starch grid was printed using a syringe attached to a XY table before and after drying. The paper shrinkage 
along the printed lines and the consequent buckling of the unprinted area are well observable. The proposed mechanism would be consistent with the evolution of the overall thickness with the CoR (a plateau was reached beyond $51 \%$, see Table 1 ). When the width of the printed line increased, compressive loading increased but the area between the printed lines decreased. Plate buckling and post-buckling behaviour is known to depend on the slenderness ratio of the plate: the lower the slenderness ratio, the higher the critical buckling load, the lower the buckled shape magnitude. Therefore, the increase of the compressive loading could be compensated by the increase of the critical buckling load beyond $51 \%$ of CoR. However, further work is needed to accurately establish the relationship between the shrinkage phenomenon and the buckling occurrence.

Indeed, another mechanism could also operate. On may assume that the water content is not constant over the paper thickness under the printed line before complete drying. It may regularly decrease from the side contacting the printed line to the opposite side of the paper. Thus, a drying shrinkage gradient may establish over the paper thickness. This could trigger the formation of a "valley" fold along the printed line (Shigemune et al. 2014). This hypothesis would be consistent with our observations, as domes always formed towards the printed side of the paper. One may assume that both phenomena (buckling and foldforming) play a part in the 3D permanent deformation of paper. Here again, further investigations are needed to conclude. It is worth noting that the (well-known) cockling phenomenon of paper is the result of the same kind of mechanisms: local buckling and local curl of paper that arise from the structural uneveness of paper coupled with its hygroexpansivity (Kajanto, 1993; Niskanen, 1998; Lipponen et al., 2008). Finally, the 3D deformation of paper obtained here by printing a starch grid and drying could be seen as a kind of "controlled" cockling.

If the proposed mechanisms are the right ones, one could predict the dome shape and the magnitude by using a buckling model provided that one has identified the right boundary conditions at the edges (i.e. the printed lines) and the right biaxial compression loading resulting from the drying shrinkage forces. Then, by using this modelling approach the grid pattern that maximizes the printed paper bending resistance could be identified. Auxetic grid patterns could also contribute to the performance improvement in a more specific way, for example by giving the printed paper a dome-like shape when it bends. However, this requires that the $3 \mathrm{D}$ structure of the printed paper can deform sufficiently during stressing. This last point should be further investigated but first tests suggested that the deformation potential of the printed papers is limited: the tensile strain at break was rather equivalent before and after grid printing.

\section{Conclusion}

Printing starch patterned grid on low basis weight packaging paper was found to be a relevant way to improve its bending performance to weight ratio. It was multiplied by at least a factor three for the $60 \mathrm{~g} / \mathrm{m}^{2}$ paper considered in this study. Therefore, a significant weight reduction of the final packaging could be achieved. As the used thermo-modified corn starch is rather standard and commercially available at low cost, and as the considered printing process has been industrially used for decades, the proposed approach may be considered as industrially viable on a technical and economical point of view.

The huge gain observed in bending performance was assumed to be the consequence of the permanent 3D shape the paper took after printing, which directly depended on the grid pattern. However, the mechanisms responsible for the paper deformation are not fully understood to this day. We assume that the drying shrinkage of the starch plays a major role. The paper in-plane compression loading that is induced along the printed lines could lead to the buckling of the unprinted zones or/and to the formation of "valley" folds along the printed lines. A better understanding is required to be able to control these phenomena. For instance, if we assume that the buckling approach is relevant, the quantity of printed starch and the grid pattern should be designed to guarantee that in-plane drying shrinkage forces exceed the critical buckling load of the unprinted areas. Thus, this approach could be applied to the lightweighting of a broader range of packaging papers, from papers of $50 \mathrm{~g} / \mathrm{m}^{2}$ to folding boards of $200 \mathrm{~g} / \mathrm{m}^{2}$ for cups or cases for instance, in view of further reducing the ecological impact of packaging. 
Funding This research was carried out within the framework of the Sherpack project which has received funding from the Bio Based Industries Joint Undertaking under the European Union's Horizon 2020 research and innovation programme under grant agreement $\mathrm{N}^{\circ} 745718$. The authors wish to thank all the people involved in this project for the exchanges during the follow-up meetings which greatly contributed to improve this work.

Data availability The authors confirm that the data supporting the findings of this study are available within the article.

\section{Declarations}

Conflict of interest The authors declare that there is no conflict of interest.

Human or animal rights This article does not contain any studies involving animals and human participants performed by any of the authors.

Open Access This article is licensed under a Creative Commons Attribution 4.0 International License, which permits use, sharing, adaptation, distribution and reproduction in any medium or format, as long as you give appropriate credit to the original author(s) and the source, provide a link to the Creative Commons licence, and indicate if changes were made. The images or other third party material in this article are included in the article's Creative Commons licence, unless indicated otherwise in a credit line to the material. If material is not included in the article's Creative Commons licence and your intended use is not permitted by statutory regulation or exceeds the permitted use, you will need to obtain permission directly from the copyright holder. To view a copy of this licence, visit http://creativecommons.org/licenses/by/4.0/.

\section{References}

Akl W, El-Sabbagh A, Baz A (2008) Optimization of the static and dynamic characteristics of plates with isogrid stiffeners. Finite Elem Anal Des 44(8):513-523

Cao Q, Huang J (2018) Experimental study and numerical simulation of corrugated steel plate shear walls subjected to cyclic loads. Thin-Walled Struct 127:306-317

Fellers C, Carlsson LA (2002) Bending stiffness with special reference to paperboard. Handb Phys Test Paper 1:233

Hirn U, Schennach R (2015) Comprehensive analysis of individual pulp fiber bonds quantifies the mechanisms of fiber bonding in paper. Sci Rep 5(1):1-9

Hubbe MA (2006) Bonding between cellulosic fibers in the absence and presence of dry-strength agents-A review. BioResources 1(2):281-318

Hubbe MA (2014) Prospects for maintaining strength of paper and paperboard products while using less forest resources: a review. BioResources 9(1):1634-1763

Huybrechts SM, Hahn SE, Meink TE (1999) Grid stiffened structures: a survey of fabrication, analysis and design methods. In Proceedings of the 12th international conference on composite materials (ICCM 12)
Johansson C, Bras J, Mondragon I, Nechita P, Plackett D, Simon P, Aucejo S (2012) Renewable fibers and bio-based materials for packaging applications-a review of recent developments. BioResources 7(2):2506-2552

Kabir S, Kim H, Lee S (2020) Characterization of 3D printed auxetic sinusoidal patterns/nylon composite fabrics. Fibers Polym 21(6):1372-1381

Kajanto I (1993) Finite element analysis of paper cockling. Prod Papermak 237-262:9

Laszczyk L (2011) Homogenization and topological optimization of architectured panels. PhD thesis, Grenoble University

Li H, Qi Y, Zhao Y, Chi J, Cheng S (2019) Starch and its derivatives for paper coatings: a review. Prog Org Coat 135:213-227

Lindström T, Wågberg L, Larsson T (2005) On the nature of joint strength in paper-A review of dry and wet strength resins used in paper manufacturing. In 13th fundamental research symposium (Vol. 1, pp. 457-562). Cambridge, UK: The Pulp and Paper Fundamental Research Society

Lindström T, Fellers C, Ankerfors M, Nordmark GG (2016) On the nature of joint strength of paper- effect of dry strength agents-revisiting the page equation. Nord Pulp Pap Res J 31(3):459-468

Lipponen P, Leppänen T, Kouko J, Hämäläinen J (2008) Elastoplastic approach for paper cockling phenomenon: on the importance of moisture gradient. Int $\mathrm{J}$ Solids Struct 45(11-12):3596-4360

Niskanen, K. (1998). Book 16: Paper Physics. Helsinki: Fapet Oy

Ren X, Das R, Tran P, Ngo TD, Xie YM (2018) Auxetic metamaterials and structures: a review. Smart Mater Struct 27(2):023001

Shigemune H, Maeda S, Hara Y, Hashimoto S (2014) Design of paper mechatronics: towards a fully printed robot. In 2014 IEEE/RSJ International Conference on Intelligent Robots and Systems (pp. 536-541). IEEE

Smardzewski J (2013) Elastic properties of cellular wood panels with hexagonal and auxetic cores. Holzforschung 67(1):87-92

Viguié J, Dumont PJJ (2013) Analytical post-buckling model of corrugated board panels using digital image correlation measurements. Compos Struct 101:243-254

Viguié J, Molina-Boisseau S, Dufresne A (2007) Processing and characterization of waxy maize starch films plasticized by sorbitol and reinforced with starch nanocrystals. Macromol Biosci 7(11):1206-1216

Wang D, Abdalla MM, Zhang W (2017) Buckling optimization design of curved stiffeners for grid-stiffened composite structures. Compos Struct 159:656-666

Wang D, Abdalla MM, Wang ZP, Su Z (2019) Streamline stiffener path optimization (SSPO) for embedded stiffener layout design of non-uniform curved grid-stiffened composite (NCGC) structures. Comput Methods Appl Mech Eng 344:1021-1050

Publisher's Note Springer Nature remains neutral with regard to jurisdictional claims in published maps and institutional affiliations. 